\title{
Reliability and Validity of Maximal Mean and Critical Speed and Metabolic Power in Australian Youth Soccer Players
}

\author{
by \\ Cameron Lord ${ }^{1}$, Anthony J. Blazevich ${ }^{1}$, Chris R. Abbiss ${ }^{1}$, Fadi Ma'ayah ${ }^{1,2}$
}

The reliability and validity of maximal mean speed (MMS), maximal mean metabolic power (MMPmet), critical speed (CS) and critical metabolic power (CPmet) were examined throughout the 2016-2017 soccer National Youth League competitions. Global positioning system (GPS) data were collected from 20 sub-elite soccer players during a battery of maximal running tests and four home matches. A symmetric moving average algorithm was applied to the instantaneous velocity data using specific time windows $(1,5,10,60,300$ and 600 s) and peak values were identified. Additionally, CS and CPᄀmet values calculated from match data were compared to CS and CPmet values determined from previously validated field tests to assess the validity of match values. Intra-class correlation (one-way random absolute agreement) scores ranged from 0.577 to 0.902 for speed, and from 0.701 to 0.863 for metabolic power values. Coefficients of variation (CV) ranged from good to moderate for speed (4-6\%) and metabolic power (4-8\%). Only CS and CPmet values were significantly correlated $(r=0.842 ; 0.700)$ and not statistically different $(p=0.066$; 0.271 ) to values obtained in a shuttle-running critical test. While the present findings identified match-derived MMS, MMPmet, CS and CPmet to be reliable, only CS and CPmet derived from match play were validated to a CS field test that required changes in speed and direction rather than continuous running. This suggests that both maximal mean and critical speed and metabolic power analyses could be alternatives to absolute distance and speed in the assessment of match running performance during competitive matches.

Key words: soccer, global positioning system, external load.

\section{Introduction}

Physical performance in soccer is commonly assessed by use of global positioning system (GPS) devices (Buchheit et al., 2014). Recent studies assessing running performance have explored the use of duration-specific movement indicators (Delaney et al., 2017; Malone et al., 2017; Roecker et al., 2017). This form of assessment applies a moving average to GPS data over specified time intervals and has been previously used to prescribe position-specific field-based conditioning drills in Gaelic and Australian Rules football (Delaney et al., 2017; Malone et al., 2017). While the use of moving average data analyses in soccer is in its infancy, an initial match-to-match variation study suggested that this form of analysis was associated with reduced between-match variability of running performance variables, particularly when assessed at higher speeds, compared to that of absolute distances achieved during match play (Lord et al., 2019).

While player displacement (distance) measures are most commonly used to quantify the physical demands of soccer (Bloomfield et al., 2007; Bowen et al., 2017; Carling et al., 2016), their association with the total metabolic work or exercise (physiological) intensity during intermittent exercise requiring frequent changes in speed and direction has previously been questioned (Polglaze et al., 2018a; Polglaze et al., 2016). Therefore, true estimations of physiological

\footnotetext{
1 - Edith Cowan University, Centre for Exercise and Sports Science Research (CESSR), School of Medical and Health Sciences, Joondalup, Australia.

2 - Curtin University, School of Education, Bentley, Australia.
} 
cost (i.e. external work load) must account for all changes in velocity (related to acceleration), as they occur in soccer (di Prampero et al., 2005; Polglaze et al., 2018a). An approach to estimate such acceleration demands proposed by di Prampero et al. (2005) makes the estimation of instantaneous metabolic power (Pmet) possible. While this approach still only accounts for locomotor demands in soccer, incorporating the cost of changing speed provides a more complete estimation of energy expenditure during variablespeed locomotion (Polglaze et al., 2018a).

The moving average analysis methodology has previously been used in the analysis of power output during road cycling races, where it was considered a useful tool for quantifying elements of cycling performance (Quod et al., 2010). Due to the variability in power output in cycling races, the analysis of maximal mean power has become a popular method of assessing a cyclist's capacity to produce power during competition (Abbiss et al., 2010; Ebert et al., 2005; Quod et al., 2010; Vogt et al., 2007). Despite power output fluctuating considerably over the course of a race, maximal mean power calculations allowed assessments of a cyclist's capacity to produce maximal power over specific time intervals (Quod et al., 2010). The curvilinear relationship between power output and time reaches a plateau at critical power (Jones and Vanhatalo, 2017). Critical power distinguishes between power output that can be sustained with stable values of muscle phosphocreatine, blood lactate and pulmonary oxygen uptake, and thus provides insight into physiological responses, fatigue mechanisms and performance capacity (Jones and Vanhatalo, 2017). This concept has also been evaluated in the analysis of speed (i.e. critical speed) during running-based events (Clarke et al., 2014). While this concept has generally been explored in laboratory and fieldbased testing environments, Quod et al. (2010) utilised the rolling average methodology (e.g. maximal mean power) to validate critical power in competitive cycling, concluding that the estimation of critical power can be performed during competition. While the likelihood of maximal intensities (e.g. speed or $P_{\mathrm{met}}$ ) for extended periods of match play is minimal due to the stochastic physical demands associated with soccer, this information could nonetheless be of use to the practitioner.

The first step towards determining the efficacy of moving average analysis methodology and the concept of critical speed and $P_{\text {met }}$ is to determine both the reliability and validity of these variables. Therefore, the purposes of this study were to examine (i) the reproducibility of maximal mean speed (MMS), maximal mean metabolic power (MMPmet), critical speed (CS) and critical metabolic power $\left(\mathrm{CP}_{\mathrm{met}}\right)$ calculations during soccer matches, and (ii) the differences in MMS, MMPmet, CS and CPmet values derived from GPS data obtained during matches versus field-based maximal effort running tests.

\section{Methods \\ Participants}

Twenty $(n=20)$ sub-elite soccer players from a National Youth League (NYL) team (age, $19.1 \pm 1.2 \mathrm{yr}$; body mass, $72.4 \pm 2.7 \mathrm{~kg}$ ) volunteered for the current study during the 2016-17 (OctoberJanuary) season. Participants trained on average 6 $\pm 1 \mathrm{hr}$ per week before the match day. All participants had a minimum of 5 years of playing experience and were familiar with field testing procedures and exercising to exhaustion. Goalkeepers were not included in the study. Before data collection, participants provided written informed consent and medical declarations were obtained. Ethical approval for the study was granted by the University's Human Research Ethics Committee (ID14821).

\section{Design and Procedures}

Participants completed three field-based test sessions, each separated by a week, before contending in the 8-match NYL competition. This allowed the reliability and validity of competition MMS, MMPmet, CS and CPmet calculations to be assessed. Four home fixtures were played on a well-maintained outdoor grass soccer pitch, and data collected in these matches were used for reliability and validity investigation. This ensured that the playing ground was consistent and that participants were not affected by interstate travel. Furthermore, investigating the match-to-match variation of four competitive matches allowed to assess the match data variation within a microcyle (analysis of a week) and a mesocycle (analysis of a month). No rain was recorded during each of the four home matches, while the temperature ranged from 29.3 to $33.2^{\circ} \mathrm{C}$ (with an average of $32.4^{\circ} \mathrm{C}$ ). 
Participants wore $15 \mathrm{~Hz}$ GPS units (SPI HPU; GPSports Systems, Canberra, Australia) during all field test sessions and throughout NYL competition, which recorded positional data at 5 $\mathrm{Hz}$. Each $5 \mathrm{~Hz}$ data point was extrapolated to create two extra data points for either side of the measured value. Previously, GPS technology has shown to be effective at providing acceptably valid and reliable measures of locomotor activity (Barr et al., 2019). GPS units were inserted into the back of a vest top which was worn under the training and competition jerseys, with the unit positioned in the centre of the upper back area slightly superior to the scapulae apexes. All GPS units were activated at least $30 \mathrm{~min}$ prior to data collection to allow for the acquisition of satellite signals, as per manufacturer's instructions. To minimise the effect of inter-unit error, each player was allocated the same unit throughout the study. All participants were familiarised with the GPS units as part of their day-to-day training and competition practises.

Field Test Protocols

Participants were instructed to arrive to each of the three field test sessions one hour before the allocated start time in a rested and fully hydrated state, avoiding strenuous exercise in the $24 \mathrm{~h}$ preceding the test. Each field test session was completed at the same time of day, with 7 days between tests. They wore the same equipment (soccer boots and shin pads) and attire (socks, shorts and shirt) that they would normally wear during competition.

Before each test, participants completed a standardised warm-up consisting of $5 \mathrm{~min}$ of dynamic movements (i.e. jogging) followed by 5 min of dynamic stretching (focussing on the lower limbs). Participants were instructed to cover the set distances, as described below, in the fastest time possible, with runs recorded manually to the nearest second using a stopwatch (S056-4000, Seiko, Japan) (Galbraith et al., 2014). Distancetime data were used to calculate maximal critical values for speed and $P_{\text {met }}$ from the three set distances covered during both straight line and shuttle critical speed field tests. Participants were not provided feedback on the elapsed time of runs.

Maximal Straight-line Running Efforts

A 400-m running track (consisting of two circles with a radius of $32 \mathrm{~m}$ at both ends of two 100-m straight line tracks) was created to test for maximal running efforts over 40, 100 and $400 \mathrm{~m}$. Markers were placed at 0,40 and $100 \mathrm{~m}$ to indicate the specific distances. To ensure that participants completed the distances at maximal speed, and that no reduction in speed over the set distances was evident, different coloured markers were placed at 2 (also facilitating $402 \mathrm{~m}$ ), 42 and $102-\mathrm{m}$ points. Participants were instructed to complete each of the three runs to the second marker to ensure speed reductions did not occur before the completion of 40, 100 and 400-m distances. Participants were given $10 \mathrm{~min}$ passive recovery between each run.

Critical Speed Field Test - Straight Line

Based on the CS field-test methodology of Galbraith et al. (2014), a 400-m running track (as used in Maximal Straight-line Running Efforts) was created to allow participants to complete 1200,2400 and $3600 \mathrm{~m}$ of continuous running (3, 6 and 9 laps, respectively). A marker was placed at $0 \mathrm{~m}$ as the starting point for each run and to track the completion of laps. Runs were conducted in the order of the longest ( $3600 \mathrm{~m}$; 9 laps) to the shortest (1200 m; 3 laps) distance (i.e. lowest to highest mean speed), matching the methodologies used in cycling and running based research (Galbraith et al., 2014; Jenkins and Quigley, 1992). One previous investigation examining the effect of $30 \mathrm{~min}$ and $60 \mathrm{~min}$ of passive recovery between 1200,2400 and 3600-m runs performed on the same day showed no effect of recovery time (Galbraith et al., 2014). Therefore, participants rested for $30 \mathrm{~min}$ between each run, with active recovery involving walking and slow jogging. Critical Speed Field-Test - Shuttle-Running

Adhering to the CS shuttle running field test protocol of Clarke et al. (2014), a 100-m straight line track was marked out and participants performed three maximal shuttle-run efforts over $100 \mathrm{~m}$ (1 length), $400 \mathrm{~m}$ (4 lengths) and $1500 \mathrm{~m}$ (15 lengths). Participants performed active recovery involving walking and slow jogging for $4 \mathrm{~min}$ after the 100-m effort, and 12 min following the 400-m effort (Clarke et al., 2014).

\section{Data Analysis}

During all sessions (i.e. field test sessions and competition), GPS data were logged and later downloaded using proprietary software (GPSports, Team AMS, release R1 2017.1). Team 
AMS software managed and analysed session data collected from GPS units, to provide instantaneous position and velocity output at 0.2 -s intervals after applying a smoothing algorithim to velocity data. Data files were cropped so that data were only recorded when an individual was active (e.g. when a participant was on-field during competition). The duration of each active period of play and field test sessions was also recorded. Only competition data sets in which an entire match (i.e. $90 \mathrm{~min}$ ) was completed were included in the validation and reliability investigation $(\mathrm{n}=$ 7 each game). Finally, GPS data were exported by Team AMS software to a customised Microsoft Excel (Microsoft, Washington, United States) spreadsheet, for the calculation of MMS, MMP met, $\mathrm{CS}$ and $\mathrm{CP}$ met values.

Equations outlined by di Prampero et al. (2005) were used to calculate Pmet. Symmetric (rolling) moving averages were used to filter the running speed and $P_{\text {met }}$ data using six different duration times $(1,5,10,60,300,600 \mathrm{~s})$ for each player across each competition data set with the maximal value for each duration recorded as the maximal mean value (speed; MMS, and Pmet; $\mathrm{MMP}_{\mathrm{met}}$ ) for that particular duration. For example, for a 60-s rolling average the identification of 300 data points (5 samples per second across 60 -s duration) was possible. Moving averages were applied to all sessions (competition and field tests), which allowed MMS and MMPmet comparisons to be made between competition and maximal running (including CS field-test) data. Moving averages were only applied where appropiate to the field test sessions (e.g. 1, 5, 10 and $60 \mathrm{~s}$ were applied to Maximal Straight-Line Running Effort analyes; 1, 5, 10, 60 and 300 s were applied to the Critical Speed Field Test - Shuttle). The rolling averages created a hyperbolic relationship between running speed, $\mathrm{P}_{\mathrm{met}}$ and time which was then converted into a straight line equation using a linear model for speed:

$$
\text { RS }=S^{\prime} \cdot(1 / t)+C S
$$

where RS = running speed $\left(\mathrm{m} \cdot \mathrm{s}^{-1}\right), S^{\prime}=$ speed, $\mathrm{t}=$ time (s) and CS $=$ critical speed $\left(\mathrm{m} \cdot \mathrm{s}^{-1}\right)$, and power:

$$
\mathbf{P}=\boldsymbol{P}_{\text {met }} \boldsymbol{t}^{\prime} \cdot(\mathbf{1} / \mathrm{t})+\mathbf{C P}_{\text {met }}
$$

where $\mathrm{P}=$ power output $(\mathrm{W}), P_{\text {met }}{ }^{\prime}=$ metabolic power, $\mathrm{t}=$ time $(\mathrm{s})$ and $\mathrm{CP}_{\mathrm{met}}=$ critical metabolic power $\left(\mathrm{W} \cdot \mathrm{kg}^{-1}\right)$. CS and $\mathrm{CP}_{\text {met }}$ values calculated during competition were compared to critical values derived from field test sessions using a linear distance-time model represented by:

$$
\mathrm{d}=(\mathrm{CS} \cdot \mathrm{t})+D^{\prime}
$$

where $\mathrm{d}=$ distance run, $\mathrm{t}=$ running time and $D^{\prime}=$ distance. This model was also used for the determination of $\mathrm{CP}_{\text {met }}$ during the field tests:

\section{Statistical Analysis}

$$
\mathrm{d}=\left(\mathrm{CP}_{\mathrm{met}} \cdot \mathrm{t}\right)+D^{\prime}
$$

Statistical analysis was conducted using the SPSS statistical software package (IBM SPSS Statistics, Rel. 23.0, SPSS Inc. Chicago, USA). Results are presented as mean \pm standard deviation (SD). For all maximal mean and critical values $95 \%$ confidence intervals $(95 \% \mathrm{CI})$ were calculated, as the limits of agreement were calculated for each participant to assess the variability of competition and field test data sets (Hopkins, 2000). The reliability of competitionderived MMS, MMPmet, $\mathrm{CS}$ and $\mathrm{CP}_{\text {met }}$ values was determined by calculating the within-subject variation, expressed as the coefficient of variation $(\mathrm{CV})$, typical error of estimate (TEE) and intra class correlation (ICC) using the one-way random absolute agreement model (Hopkins, 2000). These tests assisted with understanding the degree of error and the amount of variation between the competition data sets. Measures of CV and TEE were rated as either good ( 0 to $<5 \%$ ), moderate ( 5 to $10 \%$ ), or poor $(\geq 10 \%)$ (Scott et al., 2016). The strength of ICCs was classified as trivial (0.0), small (0.1), moderate (0.3), large (0.5), very large $(0.7)$, nearly perfect $(0.9)$ or perfect (1.0) (Hopkins et al., 2009). The validity of MMS, MMPmet, CS and $\mathrm{CP}_{\text {met }}$ was assessed by comparing match data to variable output derived from field-based test sessions (control). Spearman's rank correlation coefficients $\left(\mathrm{r}_{\mathrm{s}}\right)$ were used to compare field and test maximal mean and critical speed and metabolic power variables, with scores classified as little or none $(\leq 0.3)$, weak ( 0.3 to 0.5$)$, fair ( 0.5 to $0.7)$, good $(0.7$ to 0.9$)$ or excellent $(\geq 0.9)$ (Fermanian, 1984). Differences between MMS, $\mathrm{MMP}_{\text {met, }} \mathrm{CS}$ and $\mathrm{CP}_{\text {met }}$ values obtained from match versus field based tests were examined using paired samples $t$ tests. Statistical significance was accepted at $p<0.05$ for all tests.

\section{Results}

The reliability of match MMS, MMP met, CS and $\mathrm{CP}_{\text {met }}$ values is presented in Table 1. Intraclass correlation (ICC) scores ranged from large (0.577) to nearly perfect $(0.902)$ for speed values, 
and were consistently very large (0.701 to 0.863$)$ for metabolic power $\left(\mathrm{P}_{\mathrm{met}}\right)$ values. Coefficients of variation $(\mathrm{CV})$ ranged from moderate to good for speed (4 to $6 \%$ ) and $\mathrm{P}_{\text {met }}(4$ to $8 \%$ ) values. Finally, typical errors of estimates (TEE) were consistently good ( 0.2 to $4.6 \%)$ for both speed and Pmet values.
The validity of MMS, CS, MMPmet and $\mathrm{CP}_{\text {met }}$ is presented in Tables 2 and 3, respectively. Only CS $(p=0.002 ; 0.066)$ and $\mathrm{CP}_{\text {met }}(p=0.024$; 0.271) values from Critical Speed Field Test Shuttle were correlated $(p<0.05)$ and did not reveal any differences $(p>0.05)$.

\section{Table 1}

Means ( \pm SD), intraclass correlation coefficients (ICC), 95\% confidence intervals

$(95 \% \mathrm{CI})$, coefficient of variation (CV\%) and typical errors of estimate (TEE\%) for maximal mean speed (MMS), maximal mean metabolic power (MMP met $)$ using moving average windows of 1-600 s, as well as critical speed (CS) and critical metabolic power $\left(C P_{\text {met }}\right)$ values derived from competitive match play.

\begin{tabular}{|c|c|c|c|c|c|c|c|c|}
\hline & Match 1 & Match 2 & Match 3 & Match 4 & $95 \% \mathrm{CI}$ & ICC & $\mathrm{CV} \%$ & TEE $\%$ \\
\hline \multicolumn{9}{|c|}{ Speed $\left(\mathrm{m} \cdot \mathrm{s}^{-1}\right)$} \\
\hline $1 \mathrm{~s}$ & $8.0 \pm 0.4$ & $8.0 \pm 0.4$ & $8.0 \pm 0.6$ & $7.9 \pm 0.4$ & $7.7-8.2$ & 0.678 & 4.1 & 0.3 \\
\hline $5 \mathrm{~s}$ & $7.3 \pm 0.3$ & $7.5 \pm 0.5$ & $7.3 \pm 0.6$ & $7.3 \pm 0.6$ & $7.2-7.6$ & 0.577 & 5.6 & 0.4 \\
\hline $10 \mathrm{~s}$ & $6.1 \pm 0.4$ & $6.3 \pm 0.4$ & $6.1 \pm 0.4$ & $6.0 \pm 0.4$ & $5.9-6.1$ & 0.728 & 5.4 & 0.3 \\
\hline $60 \mathrm{~s}$ & $3.4 \pm 0.3$ & $3.4 \pm 0.3$ & $3.4 \pm 0.2$ & $3.3 \pm 0.2$ & $3.2-3.5$ & 0.902 & 4.3 & 0.2 \\
\hline $300 \mathrm{~s}$ & $2.4 \pm 0.2$ & $2.4 \pm 0.3$ & $2.4 \pm 0.2$ & $2.4 \pm 0.2$ & $2.3-2.5$ & 0.877 & 5.3 & 0.3 \\
\hline $600 \mathrm{~s}$ & $2.3 \pm 0.2$ & $2.3 \pm 0.2$ & $2.3 \pm 0.2$ & $2.3 \pm 0.3$ & $2.2-2.4$ & 0.872 & 5.3 & 0.3 \\
\hline CS & $3.9 \pm 0.2$ & $4.0 \pm 0.2$ & $3.9 \pm 0.2$ & $3.8 \pm 0.2$ & $3.8-4.0$ & 0.822 & 3.8 & 0.4 \\
\hline \multicolumn{9}{|c|}{ Metabolic Power $\left(W \cdot \mathbf{k g}^{-1}\right)$} \\
\hline $1 \mathrm{~s}$ & $80.4 \pm 7.8$ & $79.7 \pm 9.4$ & $78.0 \pm 8.8$ & $83.0 \pm 10.9$ & $75.8-84.8$ & 0.742 & 7.1 & 4.6 \\
\hline $5 \mathrm{~s}$ & $50.4 \pm 6.3$ & $54.2 \pm 7.7$ & $52.1 \pm 9.5$ & $52.6 \pm 8.7$ & $48.1-56.6$ & 0.862 & 7.8 & 4.2 \\
\hline $10 \mathrm{~s}$ & $39.3 \pm 4.0$ & $39.9 \pm 4.0$ & $38.6 \pm 2.9$ & $38.7 \pm 3.2$ & $37.3-40.9$ & 0.780 & 5.4 & 2.9 \\
\hline $60 \mathrm{~s}$ & $18.9 \pm 1.2$ & $19.2 \pm 0.9$ & $19.1 \pm 1.3$ & $18.5 \pm 1.6$ & $18.2-19.6$ & 0.863 & 3.9 & 0.8 \\
\hline $300 \mathrm{~s}$ & $13.6 \pm 1.3$ & $13.8 \pm 1.2$ & $13.7 \pm 1.3$ & $13.2 \pm 1.2$ & $12.9-14.2$ & 0.808 & 5.6 & 0.7 \\
\hline $600 \mathrm{~s}$ & $12.6 \pm 1.1$ & $12.9 \pm 1.5$ & $12.8 \pm 1.3$ & $12.6 \pm 1.5$ & $12.1-13.4$ & 0.722 & 7.0 & 0.8 \\
\hline $\mathrm{CP}_{\mathrm{met}}$ & $22.5 \pm 1.3$ & $22.7 \pm 0.9$ & $22.4 \pm 1.5$ & $22.7 \pm 1.4$ & $21.9-23.2$ & 0.701 & 3.9 & 3.1 \\
\hline
\end{tabular}


Table 2

Means $( \pm S D), 95 \%$ confidence intervals $\left(95 \%\right.$ CI), Spearman's rank correlation $\left(r_{s}\right)$ and $p$ values ( $p$ ) for the relationship between mean competition (across four matches) and field tests for maximal mean speed (MMS) and critical speed (CS) values determined during field test sessions.

\begin{tabular}{|c|c|c|c|c|c|c|c|}
\hline$\left(\mathrm{m} \cdot \mathrm{s}^{-1}\right)$ & $1 \mathrm{~s}$ & $5 \mathrm{~s}$ & $10 \mathrm{~s}$ & $60 \mathrm{~s}$ & $300 \mathrm{~s}$ & $600 \mathrm{~s}$ & CS \\
\hline \multicolumn{8}{|c|}{ Competition } \\
\hline Mean \pm SD & $8.0 \pm 0.5$ & $7.4 \pm 0.5$ & $6.1 \pm 0.4$ & $3.4 \pm 0.3$ & $2.4 \pm 0.2$ & $2.3 \pm 0.2$ & $3.9 \pm 0.2$ \\
\hline \multicolumn{8}{|c|}{ Maximal Straight Line Running Efforts } \\
\hline Mean \pm SD & $8.8 \pm 0.3$ & $8.6 \pm 0.3$ & $8.3 \pm 0.3$ & $6.6 \pm 0.3$ & & & \\
\hline $95 \% \mathrm{CI}$ & $8.6-9.0$ & $8.4-8.9$ & $8.1-8.6$ & $6.6-7.1$ & & & \\
\hline $\mathrm{r}_{\mathrm{s}}$ & 0.189 & 0.401 & 0.444 & -0.305 & - & - & - \\
\hline$p$ & 0.013 & 0.001 & $<0.001$ & $<0.001$ & & & \\
\hline \multicolumn{8}{|c|}{ Critical Speed Field Test - Straight Line } \\
\hline Mean \pm SD & $5.6 \pm 0.3$ & $5.5 \pm 0.3$ & $5.4 \pm 0.3$ & $5.0 \pm 0.2$ & $4.3 \pm 0.3$ & $4.2 \pm 0.2$ & $4.0 \pm 0.2$ \\
\hline $95 \% \mathrm{CI}$ & $5.4-5.8$ & $5.3-5.7$ & $5.2-5.6$ & $4.8-5.2$ & $4.1-4.5$ & $4.1-4.3$ & $3.8-4.1$ \\
\hline $\mathrm{r}_{\mathrm{s}}$ & 0.549 & 0.356 & 0.333 & 0.404 & -0.536 & -0.212 & -0.106 \\
\hline$p$ & $<0.001$ & $<0.001$ & $<0.001$ & $<0.001$ & $<0.001$ & $<0.001$ & 0.327 \\
\hline
\end{tabular}

Critical Speed Field Test - Shuttle

$\begin{array}{lllllll}\text { Mean } \pm \text { SD } & 8.7 \pm 0.3 & 8.6 \pm 0.3 & 8.3 \pm 0.3 & 6.4 \pm 0.2 & 5.3 \pm 0.3 & 4.0 \pm 0.2 \\ 95 \% \text { CI } & 8.5-8.9 & 8.3-8.8 & 8.0-8.5 & 6.3-6.6 & 5.0-5.5 & - \\ \mathrm{r}_{\mathrm{s}} & 0.173 & 0.425 & 0.483 & -0.049 & -0.536 & 0.842^{*} \\ p & 0.035 & 0.001 & <0.001 & <0.001 & <0.001 & 0.066\end{array}$

*Significant differences $(p<0.05)$ between the competition and the field test. 
Table 3

Mean ( $\pm S D), 95 \%$ confidence intervals $(95 \% C I)$, Spearman's rank correlation $\left(r_{s}\right)$ and $P$ values $(P)$ for the relationship between mean competition (across four matches) and field tests for maximal mean metabolic power (MMP met) and critical metabolic power ( $\left.C P_{\text {met }}\right)$ values determined during field test sessions.

$\begin{array}{llllllll}\left(\mathrm{W} \cdot \mathrm{kg}^{-1}\right) & 1 \mathrm{~s} & 5 \mathrm{~s} & 10 \mathrm{~s} & 60 \mathrm{~s} & 300 \mathrm{~s} & 600 \mathrm{~s} & \mathrm{CS}\end{array}$

\begin{tabular}{|c|c|c|c|c|c|c|c|}
\hline \multicolumn{8}{|c|}{ Competition } \\
\hline Mean \pm SD & $80.3 \pm 9.2$ & $52.3 \pm 8.1$ & $39.3 \pm 3.5$ & $18.9 \pm 1.3$ & $13.6 \pm 1.3$ & $12.7 \pm 1.4$ & $22.6 \pm 1.3$ \\
\hline \multicolumn{8}{|c|}{ Maximal Straight Line Running Efforts } \\
\hline Mean \pm SD & $98.2 \pm 7.5$ & $71.3 \pm 4.1$ & $54.5 \pm 2.5$ & $32.8 \pm 1.4$ & & & \\
\hline $95 \% \mathrm{CI}$ & $94.1-103.7$ & $69.1-74.5$ & $52.8-56.3$ & $31.8-33.8$ & & & \\
\hline $\mathrm{r}_{\mathrm{s}}$ & 0.162 & -0.003 & 0.270 & $-0.730^{*}$ & - & - & - \\
\hline$p$ & 0.013 & 0.001 & $<0.001$ & $<0.001$ & & & \\
\hline \multicolumn{8}{|c|}{ Critical Speed Field Test - Straight Line } \\
\hline Mean \pm SD & $46.2 \pm 8.2$ & $35.6 \pm 4.4$ & $30.0 \pm 3.1$ & $24.0 \pm 1.5$ & $20.1 \pm 1.0$ & $19.7 \pm 0.7$ & $21.5 \pm 1.5$ \\
\hline $95 \% \mathrm{CI}$ & $40.3-52.1$ & $32.5-38.7$ & $27.8-32.2$ & $22.9-22.5$ & $19.4-20.9$ & $19.2-20.2$ & $20.5-22.6$ \\
\hline $\mathrm{r}_{\mathrm{s}}$ & 0.200 & 0.444 & 0.195 & 0.222 & -0.419 & -0.289 & 0.299 \\
\hline$p$ & $<0.001$ & $<0.001$ & $<0.001$ & $<0.001$ & $<0.001$ & $<0.001$ & 0.001 \\
\hline
\end{tabular}

Critical Speed Field Test - Shuttle

$\begin{array}{lllllll}\text { Mean } \pm \text { SD } & 103.5 \pm 7.3 & 76.6 \pm 4.5 & 60.6 \pm 2.7 & 34.5 \pm 2.2 & 24.1 \pm 1.0 & 23.6 \pm 1.2 \\ 95 \% \text { CI } & 98.3-108.8 & 73.4-79.8 & 58.6-62.5 & 32.9-6.1 & 23.4-24.9 & - \\ \mathrm{r}_{\mathrm{s}} & 0.164 & 0.017 & 0.349 & 0.674 & -0.419 & 0.700^{*} \\ p & 0.001 & <0.001 & <0.001 & <0.001 & <0.001 & 0.271\end{array}$

*Significant differences $(p<0.05)$ between the competition and the field test. 


\section{Discussion}

The present findings indicate that MMS, MMP $\neg$ met, CS and CPmet values during soccer matches are reproducible. In fact, the magnitude of the intra-class correlation coefficients ranged from large to nearly perfect (0.577-0.902) for speed (i.e, MMS and CS) and was very large (0.7010.863) for Pmet values (i.e. MMPmet $\neg$ and CPmet; Table 1). Additionally, the coefficients of variation also ranged from good to moderate (4-6\%) in speed, and good to moderate (4-8\%) in Pmet values estimated from maximal mean and critical analyses. Researchers have previously applied the moving average method of analysis to GPS data and compared moving average windows that are associated with higher running speeds (e.g. 1, 5 and $10 \mathrm{~s}$ ) used to calculate MMS and MMPmet values, to absolute running distances associated with high-speed and sprint-speed running (Lord et al., 2019). The resulting lower match-to-match variability in MMS and MMPmet values compared to absolute high-speed and sprintspeed total distances obtained from match play suggests that the maximal mean method of analysis is an appropriate alternative to absolute distances achieved in soccer (Lord et al., 2019).

In order to assess the validity of MMS, MMP $\neg$ met $\urcorner$, CS and CPmet estimates in soccer, values determined in match play were compared to values derived from maximal running and CS field test data. The present findings show that MMS (Table 2) and MMPmet (Table 3) values were not validated according to established criterion values determined during the series of time trials. This suggests that, due to the intermittent nature of soccer and other influencing external factors (e.g. tactics), maximal running efforts are difficult to reproduce during match play (especially during prolonged periods of match play) due to the associated stochastic demands. Similarly, CS and CPmet values computed during the continuous running based CS field test were not the same as values calculated using match data (Galbraith et al., 2014). The continuous running demands of Critical Speed Field Test - Straight Line, compared to the intermittent and change of direction demands within soccer match play, might be problematic for the estimation of CS and $\mathrm{CP} \neg$ met. Therefore, a field test was used in which accelerations, decelerations and change of direction were imposed (i.e. Critical Speed Field Test - Shuttle) (Clarke et al., 2014). The present findings show that critical values obtained in this field-based test were similar to match data, and were shown to provide valid estimates of CS and $\mathrm{CP} \neg$ met analyses. The use of CS and CPmet estimates could be further investigated within soccer, potentially used to classify match intensities and demarcate thresholds within GPS analysis.

When using running speed data to estimate physiological cost (i.e. external work load) during intermittent running sports (when accelerations are such a prominent feature), the metabolic cost of acceleration, which substantially increases energy demands, is ignored (Polglaze et al., 2018b). Pmet, however, is derived from instantaneous values of speed and acceleration (di Prampero et al., 2005) and incorporates the cost of changes in speed which relates to a range of modes of running activity, from steady to erratically paced movement tasks which are required during match play (Polglaze et al., 2018b). While speed-derived thresholds (such as CS) showed a weaker and less consistent relationship with the internal load (i.e. heart rate) across various exercise modes in elite hockey players, CPmet provided a strong and consistent relationship and, therefore, was concluded to be a suitable threshold for the classification of intensity in team sport activity (Polglaze et al., 2018a). Therefore, incorporating an estimate of the energy cost of changing speed (i.e. CPmet) provided a more sensitive tool for classifying the intensity of variable-speed movement (Polglaze et al., 2018b). As movement demands in soccer comprise continual changes in speed and direction, the present findings suggest that estimates of GPSderived CS and CPmet during match play are both reliable and valid, are of practical use to practitioners who are tasked with monitoring an individual's capacity to perform running-based tasks during match play, and are suitable for analysing competition data within a mesocycle block (i.e. a minimum of 4 matches).

The ability to accelerate is critical to soccer performance, thus there is a need to monitor Pmet in addition to speed (Delaney et al., 2017). Duration-specific (i.e. maximal mean) movement indicators have been reported within Gaelic (Malone et al., 2017) and Australian Rules football 
(Delaney et al., 2017), suggesting that maximal mean analysis can be used to monitor running performance during match play and prescribe training. While previous duration-specific analysis utilised one minute intervals during match play (e.g. 1-10 $\mathrm{min}$ ), shorter time windows (i.e. 1, 5 and $10 \mathrm{~s}$ ) were also used in the current study. Analysing shorter duration times allows practitioners to assess an individual's capacity to achieve and maintain both speed and Pmet during high-speed and sprint running and, therefore allows training prescription based on match-play data. For example, in the current study, the average maximal speed calculated using a 5-s averaging window throughout the four matches was $7.4 \mathrm{~m} \cdot \mathrm{s}-1$ (Table 1). Practitioners could use this maximal mean data to prescribe training, for which speeds derived during match play are replicated during training (Figure 1).

\section{Conclusion}

While speed is commonly used in team sports as a principal variable for the assessment of players' external loads during match play, this method ignores the cost of changing speed, which increases energy demand. Therefore, monitoring Pmet in addition to speed would allow practitioners to quantify the cost of acceleration in team sport (i.e. soccer) in which changes of speed and direction are prominent. The present findings highlight the reproducibility of maximal mean, critical speed and Pmet estimates, and demonstrate the validity of GPS-derived CS and CPmet analyses during soccer match play. It would be useful in future research to investigate the difference between playing positions of maximal mean and critical speed and Pmet analysis, as the present findings were limited to a smaller cohort and selection of competitive fixtures. Additionally, investigation throughout a full league season so that in-season differences and training-to-competition differences can be determined will provide further insight into the utilisation and accuracy of maximal mean and critical speed and Pmet analyses in soccer.

\section{Acknowledgements}

The authors would like to acknowledge the efforts of the participants who volunteered to participate in the study, and to their football club for releasing the players.

\section{References}

\section{References}

Abbiss CR, Straker L, Quod MJ, Martin DT, Laursen PB. Examining pacing profiles in elite female road cyclists using exposure variation analysis. Br J Sports Med, 2010; 44(6): 437-442

Barr M, Beaver T, Turczyn D, Cornish S. The Validity and Reliability of $15 \mathrm{~Hz}$ Global Positioning System Units for Assessing the Activity Profiles of University Football Players. J Strength Cond Res, 2019; 33(5): 1371-1379

Bloomfield J, Polman R, O'Donoghue P. Physical Demands of Different Positions in FA Premier League Soccer. J Sports Sci Med, 2007; 6(1): 63-70

Bowen L, Gross AS, Gimpel M, Li FX. Accumulated workloads and the acute:chronic workload ratio relate to injury risk in elite youth football players. Br J Sports Med, 2017; 51(5): 452-459

Buchheit M, Allen A, Poon TK, Modonutti M, Gregson W, Di Salvo V. Integrating different tracking systems in football: multiple camera semi-automatic system, local position measurement and GPS technologies. J Sports Sci, 2014; 32(20): 1844-1857

Carling C, Bradley P, McCall A, Dupont G. Match-to-match variability in high-speed running activity in a professional soccer team. J Sports Sci, 2016; 34(24): 2215-2223 
Clarke AC, Presland J, Rattray B, Pyne DB. Critical velocity as a measure of aerobic fitness in women's rugby sevens. J Sci Med Sport, 2014; 17(1): 144-148

Delaney JA, Thornton HR, Burgess DJ, Dascombe BJ, Duthie GM. Duration-specific running intensities of Australian Football match-play. J Sci Med Sport, 2017; 20(7): 689-694

di Prampero PE, Fusi S, Sepulcri L, Morin JB, Belli A, Antonutto G. Sprint running: a new energetic approach. J Exp Biol, 2005; 208(Pt 14): 2809-2816

Ebert TR, Martin DT, McDonald W, Victor J, Plummer J, Withers RT. Power output during women's World Cup road cycle racing. Eur J Appl Physiol, 2005; 95(5-6): 529-536

Fermanian J. [Measuring agreement between 2 observers: a quantitative case]. Rev Epidemiol Sante Publique, 1984; 32(6): 408-413

Galbraith A, Hopker J, Lelliott S, Diddams L, Passfield L. A single-visit field test of critical speed. Int J Sports Physiol Perform, 2014; 9(6): 931-935

Hopkins WG. Measures of reliability in sports medicine and science. Sports Med, 2000; 30(1): 1-15

Hopkins WG, Marshall SW, Batterham AM, Hanin J. Progressive statistics for studies in sports medicine and exercise science. Med Sci Sports Exerc, 2009; 41(1): 3-13

Jenkins DG, Quigley BM. Endurance training enhances critical power. Med Sci Sports Exerc, 1992; 24(11): 1283-1289

Jones AM, Vanhatalo A. The 'Critical Power' Concept: Applications to Sports Performance with a Focus on Intermittent High-Intensity Exercise. Sports Med, 2017; 47(Suppl 1): 65-78

Lord C, Blazevich AJ, Abbiss CR, Ma'ayah F. Estimes of maximal mean and critical speed and metabolic powers in Australian soccer. Int J Sports Med, 2019; Under review

Malone S, Solan B, Hughes B, Collins K. Duration specific Running performance in Elite Gaelic Football. J Strength Cond Res, 2017;

Polglaze T, Dawson B, Buttfield A, Peeling P. Metabolic power and energy expenditure in an international men's hockey tournament. J Sports Sci, 2018a; 36(2): 140-148

Polglaze T, Dawson B, Peeling P. Gold Standard or Fool's Gold? The Efficacy of Displacement Variables as Indicators of Energy Expenditure in Team Sports. Sports Med, 2016; 46(5): 657-670

Polglaze T, Hogan C, Dawson B, Buttfield A, Osgnach C, Lester L, Peeling P. Classification of Intensity in Team Sport Activity. Med Sci Sports Exerc, 2018b; 50(7): 1487-1494

Quod MJ, Martin DT, Martin JC, Laursen PB. The power profile predicts road cycling MMP. Int J Sports Med, 2010; 31(6): 397-401

Roecker K, Mahler H, Heyde C, Röll M, Gollhofer A. The relationship between movement speed and duration during soccer matches. PloS One, 2017; 12(7)

Scott MT, Scott TJ, Kelly VG. The Validity and Reliability of Global Positioning Systems in Team Sport: A Brief Review. J Strength Cond Res, 2016; 30(5): 1470-1490

Vogt S, Schumacher YO, Roecker K, Dickhuth HH, Schoberer U, Schmid A, Heinrich L. Power Output during the Tour de France. Int J Sports Med, 2007; 28(9): 756-761

\section{Corresponding author:}

Dr. Fadi Ma'ayah

GPO Box U19876845 Perth

Australia

Tel: 0408950288

fadi.maayah@curtin.edu.au 